Revista Española de Antropología Americana ISSN: 0556-6533

http://dx.doi.org/10.5209/reaa.71749

\title{
Espacios, lugares, territorios y regiones. Hacia una (re)definición del Totonacapan como región
}

\author{
Víctor Vacas Mora ${ }^{1}$
}

Recibido: 18 de marzo de 2019 / Aceptado: 30 de septiembre de 2019

Resumen. La región ha sido un elemento esencial en la investigación social e histórica. Escorada como concepto a partir de los años 90, este artículo pretende repasar su historia, así como reabrir el debate sobre su actual pertinencia para un espacio concreto del México contemporáneo: el Totonacapan. A partir de un breve recorrido por su genealogía y las diversas formas en que varias corrientes han delimitado la región, trataré de ver si dichas maneras en que se ha conceptualizado se mantienen vigentes a día de hoy en relación al espacio regional propuesto, para finalmente y cerrando el trayecto, esbozar a partir de mi experiencia de campo concreta una posible reelaboración válida por contemporánea.

Palabras clave: espacio; región; Totonacapan; relaciones sociales y relaciones de poder.

\section{[en] Spaces, Places, Territories and Regions. Towards a (re) Definition of Totonacapan as Region}

\begin{abstract}
Region has been an essential concept on social and historical investigation. Put aside as concept since 90's, this paper aims to review its history as well as reopens its actual pertinence for a specific space of contemporary Mexico: Totonacapan. From a brief itinerary by its genealogy and the diverse forms in which several academic trends has demarcated region, I'll try to see if such ways are still current in relation to proposed regional space, for finally and closing the journey, draw from my field experience a possible rework, valid for contemporary.

Keywords: space; region; Totonacapan; social relationships and power relationships.
\end{abstract}

Sumario. 1. Introducción. 2. La región en Antropología. 3. El Totonacapan como región. 4. Hacia una (re)definición del Totonacapan. 5. Conclusiones. 6. Referencias.

Cómo citar: Vacas Mora, Víctor. 2020. "Espacios, lugares, territorios y regiones. Hacia una (re)definición del Totonacapan como región”. Revista Española de Antropología Americana 50: 167-189.

1 Investigador independiente.vvmora@yahoo.es. 


\section{Introducción}

Como tantos otros empleados por las Ciencias Sociales, y en lo que a su definición se refiere, el concepto región se mantiene irreductible a consenso. Han sido múltiples los acercamientos a un elemento que, como noción de importancia, criterio enmarcador y contextual de estudios e investigaciones, sigue presente en muchos trabajos y proyectos. En este sentido, se le puede situar al mismo nivel que otros que, pese a su ambigüedad semántica, así como su paulatina deconstrucción teórica y subsecuente traslado desde el mundo de lo real y lo sustantivo hasta el reino de las ideas y lo nominal, han sido y siguen siendo importantes conceptos, motores de investigación y, por lo mismo, utilizados axialmente en las ciencias humanas.

No se trata aquí, ni mucho menos, de realizar una revisión exhaustiva de sus acepciones o formas de uso en antropología a lo largo de su historia como disciplina, lo cual podría llenar un estudio de más de un volumen. Ni tampoco se pretende ofrecer una definición definitiva para el concepto de región o enunciar un listado de las que se han formulado. Se aspira a realizar un breve bosquejo, perfilado a pinceladas, que permita al lector hacerse una idea general de un panorama regido más por el disenso y la polisemia antes que por el consenso unánime y el acuerdo general entre académicos. De esta forma, mi propósito en este texto será aproximarme al concepto región a partir del tratamiento que ha recibido en parte de la literatura precedente para, a continuación, descender al espacio regional donde se ubican algunos de mis intereses y observar en qué manera las diferentes formas de emplear tal noción en antropología resultan aplicables o no al Totonacapan. Hecho esto, procederé a realizar algunas consideraciones finales al respecto que, si bien y sin duda no despejarán la polémica en torno al contenido y al empleo del término, sí podrían aportar un grano de arena a la reflexión teórica tocante al concepto "región" en su aplicación a un espacio mexicano concreto.

El Totonacapan, espacio por donde los dioses abandonaron Mesoamérica y mismo lugar por donde años después regresarían en forma de pálidos y barbados extraños, se analizará a partir de lo rescatado durante un breve recorrido por la nutrida discusión teórica en torno a la región, como concepto, y el enfoque regional, como método. Una vez revisada la pertinencia o inoperancia de los criterios extraídos de la recapitulación teórica previa, y puestos a prueba en su conceptualización como región, pasaré a extraer, en un breve corolario, algunas reflexiones finales sobre la región a partir de la experiencia concreta presentada.

\section{La región en Antropología}

El concepto región es un viejo conocido de la Antropología, casi desde su configuración como disciplina académica. Proveniente en sus orígenes de la Geografía ${ }^{2}$, ha sido empleado en diversas materias con muy distintas enunciaciones, objetivos y alcances: biólogos, circunscribiendo nichos ecológicos y ecosistemas; economistas, espacializando la organización de los recursos y de la población, así como la rela-

\footnotetext{
"El concepto de región es un concepto geográfico y, en consecuencia, es el espacio donde se desarrolla la vida humana, espacio que es transformado por la vida del hombre" (Viqueira 2001: 17).
} 
ción observable entre ellos; arqueólogos, en busca de límites para la distribución espacial de complejos de restos materiales en momentos temporales concretos (los llamados "horizontes"); geógrafos, en sus descripciones de las formaciones históricas de los territorios (siempre condicionada por los aspectos fisiográficos y por la incesante actividad humana); historiadores, rastreando patrones de arraigo espacial de los acontecimientos, una "geografía histórica" que explique el espacio a través de la historia y la historia a través del espacio; y por último, antropólogos, contextualizando el estudio de las actividades humanas dentro de marcos espaciales, ambos en condicionamiento mutuo.

Entonces, y una vez lo dicho, el concepto de región no puede considerarse unívoco. Si aceptamos que "ciertos fenómenos - no todos- exigen, para su estudio, ser diferenciados en términos de un espacio, que a su vez se definirá en términos relativos a la conceptualización del fenómeno y, por tanto, en oposición a otros espacios regionales" (de la Peña 1981: 156), asentimos a que la región, como espacio, es conceptualizada por el investigador a partir de su problema de estudio. Sin embargo, tal propósito, antes que exento de escollos, se encuentra repleto de dificultades que van desde los límites que, impuestos a dicho espacio físico, conformarán la región, los criterios en su definición, hasta los rasgos diacríticos de su caracterización, así como un largo etcétera de cuestiones no menos relevantes para configurar el concepto de manera adecuada y coherente.

En Antropología, como no podía ser de otra forma, la categoría región empezó a usarse con relación a la cultura. En Estados Unidos, escuela que utiliza el término área cultural $^{3}$ en lugar de región, es Franz Boas, a decir de Kroeber, quien acuña el concepto. Clark Wissler, alumno de Boas, lo desarrollará a partir de la noción de "rasgo cultural". Esta forma de asumir el área cultural parte de la convicción de que las fronteras de estas regiones no son marcadas por el investigador, sino que son inherentes al fenómeno en sí. Si bien hacía cierto hincapié en el medio ambiente geográfico en su relación con la cultura, su centro de análisis eran los rasgos culturales en su difusión por un territorio desde su "centro" (core area) hasta su paulatina desaparición en lo que serían entendidos como sus límites. No obstante, el área cultural dejaba fuera de juego, inobservados o tocados tangencialmente, aspectos transcendentales en la conformación regional, tales como la economía, las formas de producción, la distribución de lo producido, el poder y la política.

Será Julian Steward, discípulo de Kroeber, quien profundice en estas dimensiones en relación con las regiones. La descripción que realiza de ellas se basa principalmente en la relación de los grupos con el medio ambiente, en base a factores ecológicos y a la interacción humana con ellos: la tenencia de la tierra, la producción o recolección de alimentos, su circulación y distribución, y el tipo de sociedad que se deriva a partir de ello. Elabora un proyecto pionero para estudiar un área sociocultural, un área de relación entre centros urbanos y regiones agrícolas. En su estudio en

\footnotetext{
En su opinión, "los nativos del Nuevo Mundo podrían agruparse en términos de un solo rasgo cultural, lo cual daría como resultado el delimitar áreas según alimentos, áreas de acuerdo al vestido, áreas cerámicas, etcétera. $\mathrm{Si}$, por otra parte, tomamos simultáneamente en consideración todos los rasgos y combinamos nuestro punto de vista enfocado a lo social [...] es posible formar grupos bastantes consistentes. Esto daría áreas culturales [...]" (Wissler, citado en Viqueira 2001: 72-73). Años más tarde, agregará: "cada grupo cultural tiene su geografía, dado que un complejo cultural no se encuentra irregularmente distribuido, sino que por el contrario se encuentra apiñado en grupos. De lo que acabamos de decir se sigue que la segregación de un tipo de cultura delimita un área geográfica" (ibid.: 73).
} 
Puerto Rico pone el acento en la producción agrícola para diferenciar, dentro de la cultura nacional, subculturas, subáreas culturales, según el tipo de producción agrícola: café, azúcar y tabaco. En su opinión, el área cultural debe ser considerada como un sistema sociocultural bien integrado, producido por la relación entre centros urbanos, con demandas económico-productivas, y regiones agrícolas proveedoras de dichas demandas. Con ello, y la noción metodológica de "niveles de integración sociocultural", Steward transcendía los estudios de comunidad para ver cómo éstas se integraban a lo largo de periodos históricos en áreas socioculturales de economía y producción determinadas por las demandas citadinas y las condiciones ecológicas e históricas.

Pero las regiones también pueden afrontarse desde criterios históricos (como insistía Steward), de grandes obras hidráulicas (como señalaba Karl Wittfogel) y desde el control político. Buen ejemplo de ello es el estudio sobre la región del Acolhuacan, antiguo reino de Texcoco, realizada por Ángel Palerm y Eric Wolf (1992), quienes en su proceso relacionan estos tres elementos. Los autores toman en consideración al realizar el estudio la diversidad geográfica (la dividen, en consecuencia, en cuatro subregiones), la diversidad étnica y la complementariedad de las actividades de las zonas naturales, refiriéndose a esta zona como "área clave" o "core area"4. El estudio de Palerm y Wolf, si bien se corresponde con una región hidráulica, también tiene mucho del concepto de región histórica dada la preocupación y centralidad concedida a los procesos diacrónicos en la conformación de la región (migraciones, aculturación, contactos) y de región política (definitivamente, serán a partir de relaciones de poder que se desarrollen las obras hidráulicas, un poder que unifique el territorio, configurándolo como región): la conformación regional se constituye por el factor político que, a través de una sucesión histórica determinada, cohesiona bajo su control una zona marcada por la heterogeneidad, diversa geofísicamente, de escasa demografía y pluralidad cultural. Los autores concluyen que la transformación del Acolhuacan Septentrional de área marginal a área clave, homogénea y unificada como región, se produce por un triple proceso, cronológicamente situado: transculturación, integración política y, finalmente, obras hidráulicas.

Si con Ángel Palerm y Eric Wolf comenzamos a entrever el factor político, la hegemonía y las relaciones de poder como posibles ejes rectores en la constitución regional, será Gonzalo Aguirre Beltrán (1991) quien, continuando las ideas de Manuel Gamio, nos sitúe de lleno en las regiones sociopolíticas, espacios configurados desde la acción preeminente y dominante de un centro rector. El concepto de región de Aguirre Beltrán se origina a partir de la crítica a los estudios de comunidad, que las entendían como entidades sencillas y aisladas. De ahí, su propósito es demostrar la necesidad de incluir la comunidad como parte de un todo complejo, como parte de la sociedad mayor.

Abandonando el estudio de comunidades autocontenidas se consigue establecer la existencia de un sistema regional, marcado por un centro rector (antaño la ha-

\footnotetext{
Término que ya apareciera en Wissler en referencia al centro de las áreas culturales, allí donde la cultura en cuestión sería más "pura" y punto desde donde se dispersaría hacia la periferia del área, donde se mezclaría con rasgos culturales de áreas vecinas; o en Steward, donde el "core area" estaría formado por los rasgos culturales que no se refieren a las actividades básicas para obtener alimento). En el estudio de Palerm y Wolf la noción no se usa en ninguna de las dos acepciones anteriores, sino que es un concepto dinámico, correspondiente al territorio cuya organización inicial posibilitó una evolución hasta constituir el centro de un Estado (Viqueira 2001).
} 
cienda, hoy en día, la ciudad), en torno a los cuales gravitan una pluralidad de comunidades indígenas dependientes. Entonces, en opinión del autor, sería un sistema determinado por la presencia de un centro rector, ladino o mestizo, rodeado de una constelación de comunidades indígenas subordinadas. Formula este modelo a partir de investigaciones en la región tzeltal-tzotzil chiapaneca. Esta unidad territorial expresa una situación de relación intercultural y, al mismo tiempo, una relación de dominio que se traduce en la explotación económica de los indígenas y en un cierto grado de aislamiento respecto a las instituciones e ideas del Estado-Nación que, en opinión de Aguirre Beltrán, podrían alterar su statu quo y, con ello, mejorar su situación. Similarmente a las propuestas de Robert Redfield para el contexto yucateco (el continuo folk-urbano), la ciudad en Aguirre Beltrán es el foco que organiza, con su posición hegemónica, sus necesidades y sus demandas, la conformación de la región; en este caso, una región sociopolítica ${ }^{5}$.

En definitiva, Aguirre Beltrán revolucionó el panorama de los estudios regionales al asentar de lleno en su corazón las relaciones políticas de dominación y hegemonía, de dependencia y control. Relaciones que, a la postre, configuran su estructura y determinan su existencia.

Empero, posteriormente comienza una gradual toma de conciencia acerca de la formación y reformulación de regiones a partir de las relaciones a nivel mundial. En esta línea, André G. Frank (1978), con su teoría de la dependencia, o el concepto "sistema mundo" de Immanuel Wallerstein $(2003,2005)$ avanzaban en la conexión de los sistemas locales y regionales con espacios globales, conformados relacionalmente en situaciones de hegemonía y dominación político-económica. En 1998, Sidney Mintz, colaborador del ya mencionado proyecto Puerto Rico coordinado por Steward, informaba sobre las limitaciones de la investigación que llevaran a cabo en la isla caribeña. De esta forma, hacía notar las dificultades para aplicar el concepto de integración de áreas socioculturales al contexto nacional ya que las áreas dedicadas a los productos de exportación (café, azúcar y tabaco) quedaban integradas antes a los sistemas de mercado internacional que al nacional, siendo el desarrollo de las áreas socioculturales producto de la demanda en el sistema central (internacional), y no producto de procesos locales-nacionales. Lo que sí ofrecen las localidades son las condiciones adecuadas para la producción del producto demandado. Desde ese momento, el concepto de región no ha dejado de inspeccionarse en busca de vínculos más allá del nivel nacional, ligas cuya existencia diera forma a la organización o modificación regional a partir de intereses de explotación económica concretos.

Aunque cabrían otros muchos ejemplos extraídos de la ubérrima discusión teórica y metodológica con relación a una noción de crasa importancia en la antropología, no creo oportuno extenderme más en esta dirección. Desde luego, el concepto de región "ha sido tal vez clave en la historia de la antropología mexicana. Desde sus inicios, la disciplina ha buscado transcender los estudios puramente localistas, 'de comunidad', para situar los fenómenos observables en un contexto más amplio de organización del espacio [...]" (de la Peña 1999: 39). Pero a veces, tal relevancia

"Es sobre todo la ciudad, en la concepción de Aguirre la que jugará un papel determinante en la delimitación regional. [...] pone en circulación el término región de refugio para denominar las zonas donde viven "extranjeros en su propia tierra", sujetos a una "ecología enemiga", atrapados en una "economía dual", víctimas de un "proceso dominical" - los indios, "en dependencia y subordinación respecto a la ciudad que establece la ley y el orden y para ello emplea mecanismos de coerción física” (de la Peña 1981: 142-143). 
puede haber frenado la crítica y la revisión, corriendo así el riesgo de quedar varados en el empleo de ciertas regiones como sempiternas entidades territoriales, como si los rasgos con que se definieran (o desde los que se ha trabajado académicamente) fueran perennes marcadores de sus fronteras. Sin negar la importancia que la región aún tiene, la revisión constante y diacrónica se observa como una necesidad para determinar qué entidades regionales retienen su constitución y cuáles han sido desdibujadas por los cambios y transformaciones consecuencia de los procesos históricos que las cruzan. Pasemos a verlo en un espacio regional localizado: el Totonacapan.

\section{El Totonacapan como región}

Constante en estudios y análisis, el Totonacapan es uno de los espacios más citados en lo que a regiones mexicanas se refiere. Como importante corredor que vincula el golfo de México con el centro del país, ha jugado desde antiguo un papel preeminente en la rica historia mesoamericana. Posible destino de los constructores de la gran urbe para el periodo Clásico, Teotihuacan, granero de la Triple Alianza, así como localización del mítico Tlalocan, edénico paraíso de la cosmovisión mexica; espacio de arribo y acogida de los invasores occidentales; paraje plagado de impenetrables selvas y frondosos bosques, estriado por montañas y llanuras, bañado por caudalosos ríos y el mar, pero también tierra de fértiles suelos para la agricultura y aptas praderas para la ganadería europea; lugar, por ello, de bulliciosos puertos, grandes haciendas, ingenios y hogar de ricos mercaderes; escenario de continuados juegos de poder y abiertas luchas por su control político-económico; transitado por nutridas caravanas de insumos y mercancías, así como por contingentes militares en los veleidosos vaivenes políticos del país, desde época prehispánica hasta su entrada en el mercado internacional y los recientes hallazgos petrolíferos. El Totonacapan ha acaparado las miras y focos de atención de numerosos estudios, presente en textos científicos de diferente índole y carácter, así como lugar común en los discursos y pláticas cotidianas de sus moradores actuales.

Sin embargo, y pese a su obstinada aparición y reaparición en trabajos académicos y conversaciones casuales, ¿a qué nos referimos cuando hablamos del Totonacapan? ¿Se puede considerar el espacio así nominado como una región? Y de ser así, ¿qué criterios se pueden seguir en tal conceptualización, qué rasgos lo configuran como tal? Considero que la asunción del Totonacapan como espacio regional ha sido, en general, poco cuestionada y problematizada, lo que ha conllevado un empleo del término en un ejercicio de la costumbre, dentro de la inercia de la deriva y resaca de las corrientes académicas que se generaran largo tiempo atrás y han sido, a día de hoy, todavía poco cuestionadas.

La más minuciosa reconstrucción de lo que se entiende por Totonacapan, en cuanto a espacio limitado y acotado, se la debemos al pionero trabajo de Isabel Kelly y Ángel Palerm, quienes, en su texto de 1952 The Tajin Totonac, trazan sus fronteras para el siglo XVI a partir de la información de cronistas y otras fuentes históricas (tales como las Relaciones Geográficas). El criterio principal en su delineación fue la preparación de un mapa que señalaba los lugares donde las fuentes históricas consultadas documentaban hablantes de la lengua totonaca. Así entendido, a partir de criterios idiomáticos, el Totonacapan antiguo abarcaría desde el río Cazones al norte, hasta el curso fluvial de la Antigua, en el sur; al este lo marca la línea costera 
del Golfo de México, mientras al oeste lo cerraría la Sierra Madre Oriental, desde Pahuatlán, en el actual estado de Puebla, Jalacingo y Xalapa, en Veracruz. Un amplísimo espacio. No obstante, los autores no dieron por concluida su labor en tal punto. Con la mencionada reconstrucción realizada, procedieron a cruzar el mapa resultante para el siglo XVI con la distribución geográfica del Totonacapan moderno, a partir de la información lingüística contenida en el censo de población del año 1940. La conclusión que obtuvieron a partir de tal contraste fue la constatación de una reducción notable del territorio de la región, menguada especialmente en su zona sur.

Cuando hablamos de Totonacapan como espacio regional, estamos refiriendo, en cierta manera, una región al nombre de sus pobladores. Y, en este sentido, es difícil estimar el origen del etnónimo "totonaca" o "totonaco", del cual deriva el nombre Totonacapan: espacio donde vivían y viven los totonacos. Su etimología es lugar de desacuerdo entre los diferentes estudiosos que se han dedicado a la cultura totonaca. El principal punto de conflicto, del cual devienen dos interpretaciones totalmente diferentes, es la asignación de su procedencia, siendo las opciones dominantes para su origen el náhuatl o la propia lengua totonaca ${ }^{6}$.

La confusión alrededor de la etimología del etnónimo de donde se originaría el concepto de Totonacapan nos introduce en la escasamente elaborada polémica en torno a su sistematización como región. Si su origen como término se encuentra enturbiado por la multivocalidad, su conceptualización como región no es menos problemática. Díscola y cerril a los intentos de reducción a un criterio unificador (e incluso a la combinación de varios de ellos), la demarcación del Totonacapan elude corsés definitorios en su cohesión como entidad regional. A continuación, pretendo revisar, muy brevemente y de manera no absoluta, los diversos criterios a partir de los cuales se han definido las regiones (brevemente expuestos en el apartado previo) para ponerlos en relación con el espacio que aquí nos interesa. Tomaré los que Andrés Fábregas (2010) o Brigitte Boehm (1997) propusieran como útiles para un estudio regional: geográfico, histórico y antropológico (o cultural), a los que adiciono los cuatro tipos a los que aludía Guillermo de la Peña (1999) como característicos en la antropología mexicana: sistemas productivos regionales, mercados regionales de productos y de trabajo, sistemas de dominación regional y patrones regionales de cultura. Coincidente este último criterio con uno de los tres que presentaban Fá-

\footnotetext{
Entre los escritores que han hecho proceder del náhuatl la palabra "totonaca", ya en el siglo XVI, Bernardino de Sahagún apunta a un gentilicio despectivo. En su opinión, "totonaca", vocablo empleado por las gentes del Altiplano para referirse a los habitantes de las tierras bajas, vistos por los primeros como gente atrasada, denotaría "poca habilidad" o "poca capacidad". Kelly y Palerm (1952), tras el análisis de diferentes fuentes, avalan la versión del franciscano. Los autores concuerdan en que, con dicho término, los pobladores del Altiplano se diferenciaban y señalaban con desprecio etnocéntrico a una diversidad de grupos lingüísticos diferentes al náhuatl que, sin estar necesariamente localizados en el Totonacapan, eran considerados rudos y rústicos. Otra forma de entender el término desde su raíz náhuatl sería la que manifiestan Walter Krickeberg (1933) o Enrique Palacios (1942), autores que observan la formación de la expresión "totonaca" en la forma verbal "tona", "hacer calor" o "hacer sol". En este sentido, apuntaría a los habitantes de la tierra caliente. Sin embargo, la forma de leer el término varía notoriamente si se hace provenir etimológicamente del totonaco. En esta acepción, Francisco Domínguez, autor de un catecismo de la doctrina cristiana en idioma totonaco en el siglo XIX, o Celestino Patiño, historiador de Papantla que elaboró un vocabulario totonaco a principios del XX, sostienen que "toto" significa "tres" en totonaco mientras "naco" o "nacú" sería "corazón"; literalmente, "tres corazones". Esto es relacionado por Patiño con los tres centros rectores o cacicazgos que, en época prehispánica, organizaban el territorio que poblaba este grupo étnico (Tajín, Yohualinchan y Cempoala) y por Kelly y Palerm con los tres subgrupos lingüísticos del totonaco (Chenaut 1995).
} 
bregas y Boehm, nos quedan seis, a saber: 1) cultural, 2) geográfico, 3) histórico, 4) productivo, 5) estructuras de poder, y 6) sistemas de mercado regionales.

A partir de este cruce espero encontrarme en condiciones de demostrar que el concepto regional del Totonacapan es utilizado en muchos casos más como un vestigio heredado del pasado, válido para otros momentos históricos, que un recurso de utilidad en la vertiginosa realidad social actual. Pese a esta inoperancia para la actual situación, los académicos, por diferentes motivos, incluida la fuerza de la costumbre, hemos seguido empleando el concepto antes que reevaluarlo de acuerdo con las circunstancias actuales, casi cosificándolo como realidad sustantiva de carácter inmutable. Pasemos a verlo con mayor detalle.

\subsection{El criterio cultural o antropológico}

Si aceptamos que la región del Totonacapan toma su nombre del grupo étnico que la ocupa u ocupara en otros tiempos (ya sea otorgado por sus propios moradores, o por observadores foráneos a tal región desde el Altiplano central), podría pensarse que su definición descansa en cierto contenido cultural. En cuyo caso, se asimilaría al concepto "área cultural" previamente discutido (siendo el "rasgo cultural" privilegiado, en este caso, el lenguaje). De hecho, Kelly y Palerm (1952: 250) definían el moderno Totonacapan como el lugar donde el idioma totonaco todavía se habla. Empero, un vistazo en la actualidad a lo largo de dicho espacio nos demuestra lo insuficiente del criterio cultural o etnográfico para caracterizar la zona como región en el sentido antropológico. Si bien ya en el pasado, tal y como apuntaran Isabel Kelly y Ángel Palerm, diversos grupos lingüísticos y étnicos compartían espacio con diferentes comunidades asentadas en la zona totonaca, no es menos cierto para el día de hoy: mestizos, otomíes, nahuas y, en menor medida, tepehuas cohabitan este gran espacio junto con grupos totonacas. Este caleidoscopio de etnicidades y lenguas produce, cuando menos, recelo en referencia a observar en el Totonacapan un espacio de pretendida unidad cultural o mínima coherencia etnográfica que lo convirtiera, tomando tal criterio como rector, en región.

Por supuesto, se puede aducir (y no serán pocos quienes lo hagan) que no es necesaria la unidad cultural en la conformación de una región. Con este matiz, indicarán sus apologistas, debemos entender por Totonacapan el espacio donde habitan los grupos totonacos, aunque éstos lo hagan junto con otras etnias y grupos culturales. Efectivamente y de cara a la construcción de la región, esta visión no demandaría la exclusividad cultural al interior de una zona dada para poder hablar de región o área cultural. De esta forma, sería suficiente circunscribir el espacio que se pretende regionalizar a la distribución de un grupo cultural, aunque otros muchos lo pueblen con él. Esta estrategia permite eludir el problema de la pluralidad lingüística y cultural al interior del espacio que se pretende delimitar a partir de tales rasgos como región. Pero tal soslayamiento es solo un espejismo en la actualidad. Actualmente, y debido a las diásporas culturales y las dinámicas migratorias, el grupo totonaca puede encontrarse en una gran diversidad de espacios y lugares, desde la costa del Pacífico mexicano hasta la península del Yucatán, desde la exuberante frontera sur hasta el desértico extremo septentrional. Y aún trascender las fronteras nacionales para ubicarse en Estados Unidos, Canadá o, en menor medida (aunque conozco casos de referencia), en Europa. Es pues, hoy en día y siempre en mi opinión, inviable contener el Totonacapan a partir del espacio donde habitan los totonacos (entendidos como grupo cultural) o se habla tal idioma. 
Por ello, el concepto cultural ${ }^{7}$ en la configuración del Totonacapan como región es, para la actualidad, poco preciso, conduciendo antes a la duda y la confusión que a una clara delimitación de la zona que se pretende signar bajo tal denominación.

\subsection{El criterio geográfico}

Otra de las nociones que han permitido exitosamente delinear contornos y acotar espacios como regiones ha sido el criterio geográfico. Esta forma de imaginar la región parte de la geografía física y natural para demarcar un territorio sobre la base de una serie de características presentes en él y ausentes en las zonas vecinas y espacios adyacentes, para convertirlo, de esta forma, en una región. Es decir, partiendo de las especificidades del entorno físico y natural con el cual, inevitablemente, el ser humano deberá entrar en relación, en transformación y condicionamiento mutuo, se pretende diferenciar un espacio de otros mediante las particularidades geofísicas (incluyendo clima, fauna y flora) que en él se observan. Luis Fuentes (1972), por ejemplo, categoriza una región natural por ser un área dentro de un país o continente con una determinada estructura geológica, un clima característico con influencia sobre dicha estructura, una hidrología de particulares características, suelos definidos, y una vegetación y una fauna características.

Si bien este tipo de divisiones regionales en base a la geografía natural son pertinentes para muchos casos, el Totonacapan se muestra, nuevamente, irreductible a este criterio de cara a su conformación. La mayoría de los estudiosos que han trabajado la zona coinciden en que se pueden encontrar, por lo menos, cuatro tipos de nichos ecológicos en su interior, correspondientes cada uno de ellos a condiciones geográficas y naturales concretas y particulares. Así, geográficamente podemos detectar "dos zonas contrastantes: la Sierra, ubicada en el sistema de montañas denominado Sierra Madre Oriental, y la Llanura Costera del Golfo Norte. Entre la Sierra y la Llanura Costera existen dos zonas de transición [...]. Al interior de cada una de estas cuatro zonas hay, además, una diversidad de topoformas" (Velázquez 1995: 29). Como vemos, antes que dotar de cierta coherencia interna a la región, es la idea de región, sobreimpuesta a esta zona, la que otorga cohesión a dispares ambientes ecológicos y geográficos. Pero ¿en qué criterios basamos entonces una idea que transciende las diferencias geográficas para cohesionarlas en un mismo espacio regional?

A medio camino entre los criterios geográficos, los productivos y de distribución de lo producido, un enfoque que ha tratado de superar la problemática expuesta es el que adoptara el antropólogo Elio Masferrer (2006). Toma la noción de complementariedad vertical y de archipiélagos verticales que desarrollara para la zona andina John Murra (1975), y la aplica a la diversidad de espacios que compondrían el Totonacapan como tradicionalmente ha sido asumido. El intercambio constante entre

\footnotetext{
Un aporte muy importante es el concepto de cultura regional de Claudio Lomnitz. Sin embargo, no se debe confundir con el que se presenta aquí en cuanto al tratamiento cultural del Totonacapan (o con la noción de "área cultural"), ya que el concepto de Lomnitz de cultura regional se desarrolla dentro de una región económica-política, preexistente ésta y que actúe como matriz de formación para la cultura y comunicación o circulación simbólica común (aunque diferenciada): "Una cultura regional es aquella cultura internamente diferenciada y segmentada que se produce a través de las interacciones humanas en una economía política regional" (1995: 39). Es decir, "las regiones culturales se encuentran íntimamente ligadas a las regiones económicas y administrativas" (ibid.: 41).
} 
diversos nichos ecológicos con producciones muy diferentes (variabilidad resultante principalmente de factores geofísicos y de altitud), supliría los disímiles espacios de materias primas y alimentos, integrándose en una red de poblaciones tendentes a ocupar diferentes nichos ecológicos y productivos diseminando unidades familiares extensas a lo largo de ellos. A la vez que integrar un mosaico de espacios muy diferentes, esta postura explicaría ingeniosamente aquello que tanto sorprendió a Kelly y Palerm: la ausencia de mercados para todo este espacio en la época prehispánica. Ciertamente, la idea de Murra, trasladada por Masferrer (2006) al espacio que nos ocupa, salva el problema de la heterogeneidad física interna a la que se enfrenta esta región como concepto, y ofrece un centro gravitacional en torno al que construirlo. Pero, nuevamente, lo hace para un momento temporal concreto y en su revisión actual se muestra inoperativo como criterio unificador. A día de hoy, numerosos mercados y plazas cubren el espacio nominado como Totonacapan, así como las poblaciones no diseminan a sus habitantes en diferentes nichos ecológicos en pos de su aprovechamiento productivo complementario (respondiendo la notoria emigración a otras causas). Los arrieros, con sus recuas de animales de carga, y, posteriormente, las carreteras abiertas a lo largo de toda la zona con la distribución de mercancías con vehículos motorizados, proveen de insumos muy diversos a toda el área, eliminando la necesidad de dispersión poblacional a lo largo de diversos nichos ecológicos de cara a satisfacer cierta diversidad productiva. Si bien este aprovechamiento de diferentes espacios ecológicos pudiera ser el eje en torno al cual conceptualizar el Totonacapan como región en épocas pretéritas, la irrupción de nuevas características y contingencias históricas deshacen la opción de seguir empleando tal noción (complementariedad vertical) como un posible criterio de cohesión regional.

\subsection{EI criterio histórico}

Como ya señalé en el punto segundo, las regiones no son formaciones estáticas en el devenir temporal, sino que se configuran y reconfiguran a lo largo de procesos diacrónicos. En este sentido, es posible afirmar que toda región es histórica. Sin embargo, en ocasiones, es dable delimitar espacios geográficos que han compartido a lo largo del tiempo una serie de eventos que han permitido o favorecido la formación de estructuras comunes a todo el espacio así influenciado. Se puede hablar de una región histórica estudiando la sucesión de los diversos procesos compartidos que han confluido en la conformación de diversas estructuras afines a un determinado espacio: el ámbito espacial donde se han sucedido una concatenación de fuerzas, procesos y eventos que han modelado ciertas formas sociales, productivas, económicas, políticas o culturales (las cueles repercutirán en la sucesión de eventos futuros) compartidas en mayor o menor medida por los habitantes de un espacio así delimitado.

Igualmente, el Totonacapan se resiste a esta forma de conceptualización ya que, si bien ha compartido una serie de desarrollos históricos, aquéllos comunes a todo el espacio que se afirma que lo componen como región no son específicos a su territorio, sino que lo transcienden e integran a gran parte del territorio nacional. $\mathrm{Y}$ aquéllos que se producen específicamente al interior de su territorio aceptado como definidor no son compartidos por la totalidad de él, sino localizados en espacios concretos. Por ello, es difícil poder definir el Totonacapan a partir de una sucesión de fenómenos históricos y las estructuras surgidas de ellos. Dada la diversidad geográfica y la heterogeneidad al interior de los límites fijados como su 
contorno, los procesos diacrónicos han variado, en gran medida, acorde a la variedad de las imposiciones climáticas, orográficas, poblacionales o hidrográficas que componen el Totonacapan. Mientras en la costa se estaban sucediendo una serie de episodios históricos, con formas de propiedad, producción y relaciones sociales particulares, incluyendo esclavos africanos, rebeliones indígenas frente al abuso reiterado de los hacendados castellanos y otros desarrollos históricos circunscritos a circunstancias concretas, la Sierra permanecía ajena a ellos, imbuida en procesos de desarrollo temporal propios, determinados por diferencias palpables en formas económicas y de producción, tenencia de tierra, relaciones sociales y un largo etcétera de determinantes derivados de una historia propia (en desarrollo dialéctico con el medio natural y sus determinantes).

Es decir, y hasta aquí, que los criterios empleados por Andrés Fábregas (2010) para analizar la configuración del Chalco-Amecameca como región, o que Brigitte Boehm (1997) nos presenta como relevantes y a tener en cuenta en los estudios regionales, se nos demuestran, por sí solos, ineficaces en la definición del Totonacapan contemporáneo.

\subsection{El criterio de la producción}

Uno de los cuatro tipos de estudio regional que aísla de la Peña (1999) para la antropología mexicana, como espacio productivo, se observa poco cohesivo en la consideración del Totonacapan como región. Si bien hubo ciertos cultivos y modelos de producción comunes, sujetos a las dinámicas de los mercados y vinculados a instituciones y relaciones sociales concretas, las diferenciaciones a nivel de este criterio como conformador regional hacen muy difícil crear un cuadro mínimamente homogéneo en cuanto a "encadenamientos horizontales de instituciones, actividades y relaciones sociales" (Roberts 1980) se refiere. Y nuevamente, los condicionantes geográficos son en gran parte causantes de esta heterogeneidad en cuanto a la producción y sus estructuras. La acusada diversidad ecológica al interior de sus confines imposibilita la implementación de modelos productivos regionales, siendo necesaria la adaptación de diversos tipos y modelos de producción según el nicho ecológico y el espacio geográfico. Mientras la costa estuvo marcada por grandes haciendas y considerables extensiones ganaderas, la abrupta y anfractuosa zona de la Sierra limitó este tipo de instituciones de producción, centrándose mayoritariamente en pequeñas milpas familiares y medianas extensiones de cultivos allí donde la orografía daba permiso para ello. La caña de azúcar, extendida tanto en la costa como en la Sierra (aunque en formas de producción muy diferentes, en base a las instituciones y formas de tenencia de la tierra), no penetró en la zona meridional del Totonacapan, seca y de escasas precipitaciones pluviométricas. En época moderna, con el descubrimiento de focos petrolíferos en Veracruz, se ha profundizado en la diferenciación productiva y de los mercados de trabajo. En definitiva, el trazado de las fronteras del Totonacapan como región no puede partir de criterios de producción, ya que éstos, antes que conferir homogeneidad, introducen un buen número de diferencias, más propias para considerar varias regiones allí donde tendemos a observar, bajo el denominador Totonacapan, una única. 


\subsection{El criterio del poder: la región política}

Este criterio que introduce Guillermo de la Peña tiene base en los poderes ajenos al Estado que, ante la impotencia de éste, surgen en diversas zonas para suplir a un poder poco fuerte y centralizado, incapaz por ello de ejercer sus atribuciones en dicho espacio. Consecuencia de ello, aparecerían "poderes alternativos que se encargan de imponer un orden de acuerdo con sus intereses y alcances" (de la Peña 1999: 48). Fruto del surgimiento en determinadas zonas de liderazgos y representaciones en función de intereses y objetivos concretos a dicho espacio (determinados por la geografía física, la sedimentación de factores históricos, económico-productivos y socioculturales), el área de influencia de su poder y el espacio que cubren sus redes, podrían ser recortados como regiones. Los poderes así surgidos articularían una serie de redes, conformando una arquitectura concreta de relaciones de poder, diferenciada de otras, lo cual podría permitir, a partir del análisis de sus singularidades, delimitar una región. "Es posible", nos dice de la Peña, "en el periodo 1940-1980, distinguir espacios estructurados alrededor de figuras caciquiles [...]" (ibid.: 49). ¿Podemos aplicar este modelo de estructuración política del espacio al llamado Totonacapan?

Es tal vez factible que, para el pasado prehispánico, regido su espacio por la coalición de tres centros rectores, el Totonacapan tuviera realidad efectiva como región política, configurada a partir del ejercicio combinado de poder de las tres "capitales" sobre la totalidad del área que Kelly y Palerm consideraron que abarcaba. Pero ¿es posible seguir considerando válido este criterio para la actualidad del siglo XXI? Nuevamente, y desde mi opinión, la respuesta ha de ser negativa. $\mathrm{Si}$, como hemos indicado, los poderes y liderazgos alternativos representan ciertos intereses propios, vinculados al espacio donde el liderazgo se gesta, $\mathrm{y}$, como ya se ha apuntado, dichos propósitos estarán determinados, entre otros, por una serie de factores geográficos, históricos, socioculturales y económico-productivos (todos, descartados como factor unificador para el Totonacapan dada su pluralidad interior), se sigue indefectiblemente que estas redes de articulación del poder no pueden ser una única, con los mismos intereses y objetivos, para todo el espacio que abarca la región aquí tratada (aglutinada a partir del despliegue de dichas redes de poder a lo largo y ancho de su territorio), sino adaptados a su entorno concreto. Y por ello, no es posible como criterio guía en la relación y articulación del gran espacio rotulado como Totonacapan.

\subsection{El criterio de los sistemas comerciales}

Por último, me gustaría revisar el criterio de los sistemas comerciales a la hora de definir una región. Contamos con un pionero y deslumbrante ensayo de esta posible forma de configuración regional para Oaxaca, de la mano de Bronislaw Malinowski y Julio de la Fuente (1957), quienes trabajaron los sistemas de mercado e intercambio como redes cohesivas que integran regiones a través de sus lazos de compraventa, trueque y otras transacciones. En La economía de un sistema de mercados en México. Un ensayo de etnografía contemporánea y cambio social en un valle mexicano los autores, mediante una rica y detallada descripción etnográfica, vívido retrato de los mercados de la zona (incluyendo quiénes acuden, qué se vende y quiénes lo venden, precios de los productos, regateo, acaparadores e intermediarios, 
etc.), revelan la importancia de este tipo de redes de intercambio cohesionando cierto ámbito territorial.

Si bien, y como señalé en el punto anterior, la producción y su organización fue altamente diversa, en íntima relación con las condiciones geográficas naturales, la forma en que esta producción circula a lo largo del Totonacapan, vinculando las diferencias antecitadas, es la única estructura que convincentemente transluce cierta unión para este vasto espacio, vínculo suficiente como para asumirlo como región. Esto queda demostrado en el estudio que Emilia Velázquez realizara en 1995. En él, tras aceptar de partida la tremenda heterogeneidad y fragmentación del espacio del Totonacapan, regido más por diferencias que por puntos de encuentro, la autora llega a la conclusión de que la única cohesión regional posible ha de ser hallada en el comercio y las redes de mercadeo que vinculaban los muy diversos espacios (geográficos, productivos, de poder e histórico-culturales) que abarca esta zona del México centro-oriental. Los arrieros, con sus recuas de mulas, las rutas que éstos seguían, las plazas de mercados y tianguis jerárquicamente localizados a lo largo de sus itinerarios, así como el trasiego de mercancías y productos (de procedencia tanto interna como externa a la región así configurada), crean una red de tráfico e intercambio de insumos, alimentos y manufacturas; un tejido comercial que dota de cierta cohesión a la totalidad del espacio (por todo lo demás, diversificado) que dicha red conecta y comunica. Pese a ello, se debe tener en cuenta que diversos procesos en momentos distintos llegaron a desmembrar el sistema regional de mercadeo, produciendo dinámicas comerciales propias en algunos espacios de la región que, rompiendo con el resto del área, las excluirían de la idea regional configurada a partir de los lazos mercantiles. Incluso, y como Emilia Velázquez (1995) denota, a la hora de analizar los sistemas de organización mercantil se constatan dos muy diferentes: uno para la Sierra con carácter solar, mientras que la costa cuenta con un sistema dendrítico (cf. Nash 1979; de la Peña 1986; Smith 1991).

Efectivamente, los sistemas de comercio y mercadeo, con base en sistemas de producción diferenciados y localizados, que conectaron de extremo a extremo esta región, ofreciendo un escenario coherente en la delimitación del espacio en conjunción con la actividad humana, la comunican con el nivel nacional y con el ámbito internacional. Sin embargo, las dinámicas en los mercados nacionales e internacionales, incidiendo en la organización al interior del Totonacapan, han terminado por diferenciar y desconectar las rutas comerciales al interior de la región, desgajando zonas del resto para relacionarlas con espacios más allá del ámbito regional. Cuando pasa esto, en el momento en que este criterio unificador deja de cohesionar la diversidad al interior del conjunto, ¿podemos, aún y todo, seguir hablando de la región del Totonacapan desde los sistemas de intercambio? Si como espacio comercial y de mercadeo común ya no se aglutina como área, con zonas y espacios internos desligados de su tradicional trasiego comercial y asociados al ámbito nacional o internacional, ¿es posible considerarla aún una región comercial?

\section{Hacia una (re)definición del Totonacapan}

He repasado una serie de estrategias metodológicas en la configuración del espacio como región intentando aplicarlas al Totonacapan en su delimitación como tal a día de hoy. En el trayecto he ido desechando cada una de ellas no por inapropiadas, ni mucho menos, sino por su carácter sincrónico y su incapacidad de ser proyectados 
más allá de un determinado momento o periodo histórico. Una de las soluciones que (consciente o inconscientemente) se han tomado frente a este desgaste del gran Totonacapan en su asunción no problematizada como región, ha sido moverse "hacia abajo", a sus subregiones (espacios considerados tradicionalmente como componentes de una región mayor), para asumirlas como regiones con pleno derecho ${ }^{8}$.

Yo aquí, sin embargo, quiero proponer una solución alternativa que permita (re) conceptualizar el Totonacapan como región a partir de un criterio válido por contemporáneo. A partir de mi experiencia investigadora concreta ${ }^{9}$, aunada a las propuestas de algunos autores, trataré de enunciar lo que desde mi punto de vista podríamos entender como Totonacapan a día de hoy, atendiendo principalmente a cómo se pone en juego el concepto en las relaciones sociales del espacio que idealmente abarca. Para ello, retorno al valioso aporte de Lomnitz-Adler: su noción de región cultural, y la comunicación entre culturas íntimas ("cultura de relaciones sociales") ${ }^{10}$.

En esta dirección, y como algo evidente, debemos comenzar por recordar que el espacio no puede ser conceptualizado de forma ajena a los actores sociales que en él moran. Son estos últimos quienes, con sus actividades, prácticas, relaciones y desplazamientos, convierten el espacio en lugar, lo dotan de significados y contenidos (culturales, sociales, económicos, políticos, de poder). Y si el espacio no debe ser atendido como un ámbito naturalmente dado, esto es, objetivo y ajeno a los actores que entran en relación con él, sino que por el contrario se configura en reciprocidad con los agentes, sus relaciones sociales y su visión cultural (especialmente en sus prácticas, actividades, usos y movilidad corporal en el entorno), debemos reconocer que, para conceptualizar una región, el punto de partida debieran ser los actores sociales, sus prácticas, tanto entre sí en el espacio como en su relación recíprocamente constituyente con el entorno físico. De esta forma, el espacio y los agentes portadores de una dimensión social y cultural, así como dentro de relaciones de poder, entran en configuración mutua, posibilitando lecturas del entorno físico que lo convierte en lugares significantes (cuya articulación conformaría el paisaje cultural, que dentro de

8 Así, por ejemplo, la Sierra Norte de Puebla se ha tomado en ciertos estudios como una región en sí misma, componente en ciertas coyunturas pretéritas de un espacio integrado mayor, el Totonacapan, actualmente incoherente e inoperativo a todos los criterios que hemos repasado en su conceptualización como una región. Es la opción que tomó, por ejemplo, Andrés Ruiz Lombardo (1991) en su estudio de la economía cafetalera en una comunidad totonaca o el reconocido trabajo de Bernardo García Martínez (1987) sobre la configuración del espacio indígena en la Sierra Norte de Puebla en relación con las dinámicas del poder hasta el año 1700. Aquí, el diseño de la geografía se relaciona con las políticas coloniales y la distribución de los sujetos de control en el espacio de acuerdo con pretensiones sociopolíticas, pero ceñido todo ello al marco regional de la Sierra Norte de Puebla y sus características.

9 Concretamente, un total de año y medio en la zona en dos temporadas de trabajo de campo. La primera, seis meses entre los años 2005 y 2006, y la segunda, un año entero durante el 2011 y 2012 . Espacialmente, el ámbito del trabajo de campo se concentró en el extremo norte de la Sierra, desde Villa Ávila Camacho (La Ceiba, popularmente) y la carretera nacional 130 hacia la muerte del Estado de Puebla entre Veracruz e Hidalgo. Pero también, cuantiosas visitas a los centros rectores mestizos tales como Huauchinango, Zacatlán, Xicotepec de Juárez, Chignahuapan, Tuxpan, Poza Rica o incluso Tulancingo. En todo este tiempo, los interlocutores fueron tanto totonacos en diferentes posiciones sociales dentro del contexto regional (desde peones asalariados, pequeños propietarios de autosubsistencia hasta propietarios con parte de producción agrocomercial), como no indígenas, abarcando éstos posiciones diversas en el entramado socioeconómico y productivo de la región (maestros, políticos, terratenientes, obreros asalariados, mercaderes).

10 Lomnitz-Adler define la "cultura íntima" como "la cultura de una clase en un ámbito regional específico", en contraposición a la "cultura de relaciones sociales", la que considera como "el campo simbólico en el que se establecen objetivamente las relaciones de poder entre culturas íntimas” (1995: 47). 
patrones de control -político y/o simbólico-deviene en territorio); atendiendo a todo ello, para el investigador, es dable hablar de región ${ }^{11}$.

Mi propuesta, entonces, sería reconducir nuestro enfoque a las relaciones sociales, allí donde las nociones abstractas toman concreción empírica para los agentes sociales (verdadera preocupación de la antropología) y, con ello, realidad social en un entorno (cultural, económico, político) concreto. Y para hacerlo, recurro a los conceptos que propusiera Lomnitz-Adler en su conceptualización de las regiones. Con ello, y por un lado, evitaremos caer en nociones estructurales ajenas a los actores sociales y las relaciones que entre ellos se instituyen. Por otro, convertimos el concepto región en algo "vivo", asociado a un uso social espacialmente localizado, soslayando su petrificación como algo perenne y ajeno a aquellos agentes que lo dan "vida", o entrar en debates sobre su "realidad" a partir de condicionantes no antrópicos.

Atendiendo a lo descrito sobre ella por parte de diferentes autores (García 1987; Velázquez 1995; Masferrer 2006), podemos considerar el Totonacapan como un espacio regional marcado por un fuerte control de una minoritaria elite mestiza, clase dominante en base al monopolio comercial de la producción agrícola en la zona de la Sierra Norte, además de acaparar grandes haciendas y ranchos ganaderos en la Llanura Costera. En sus pretensiones hegemónicas, y dependiendo de las zonas, dicho grupo movilizó una serie de estrategias económico-políticas (como el acaparamiento de tierras o de las instituciones rectoras y económicas al nivel regional y, siempre que tuvieron la opción y el interés, al nivel local), así como desarrollaron una ideología que, mientras justificaba su posición relevante en la "cultura de relaciones sociales", confinaba al indígena en un papel subordinado, sujetos subalternos cultural, social, política y económicamente ${ }^{12}$.

11 Emilia Velázquez (2001: 21), preocupada por diferenciar región de territorio, concluye que "la región es el ámbito privilegiado de reproducción de la "cultura de relaciones sociales" de que habla Lomnitz-Adler (1995), en tanto que el territorio sería el espacio donde se reproducen las "culturas íntimas" (ibid.), aquellas que dan identidad a un sector localizado de una clase social, pero también a un grupo étnico. Es decir, la singularidad a partir de la cual se establece la relación con los "otros" se construye en el territorio, que es "un espacio a la vez de dominio y de "intimidad protegida"” (Gatti 1987: 10). El territorio y la región son, entonces, dos espacios de relaciones sociales que no se contraponen ni excluyen, sino que se complementan" (Velázquez 2001: 21).

12 Los mestizos de la región heredan de la época colonial una imagen del indígena que justifica tanto la sujeción subordinada de éste como la posición preeminente de aquéllos. En la ideología mestiza de la zona, el "indio" (también e igualmente en forma despectiva, "naco" o, en menor medida, "apache") es observado y tratado como "menor de edad", como un conjunto de sujetos apegados al ámbito natural que se desenvuelven en mundos de superstición y "brujería", incapaces de comprender y adecuarse al mundo contemporáneo y sus dinámicas. Cómo no "entienden" cómo opera la realidad, recurren a la magia y a comportamientos irracionales de una "costumbre" inveterada, heredada de sus antepasados e imaginada como invariable a través del tiempo (es decir, el "indio" es y ha sido siempre "indio", sin capacidad de "redención". Un sujeto fuera de la historia). Esta proyección permite y sustenta la clasificación identitaria que todavía se mantiene fuertemente vigente en la región como "gente de costumbre” y "gente de razón”. Dado que se encuentran más apegados a la naturaleza, son considerados más próximos a los animales que a las personas, atribuyéndoseles la capacidad de abastecerse del entorno sin casi esfuerzo o trabajo alguno, lo que habilita catalogarlos de holgazanes y vagos; por lo cual hay que vigilarles y supervisarles si se quiere que trabajen y "prosperen". Al mismo tiempo, dado que sus habilidades como sujetos naturales, casi "salvajes", les permiten alimentarse y vivir con solvencia en su medio, en las relaciones capitalizadas que se instituyen entre ambos grupos, se asume que necesitan de poca o ninguna remuneración para subsistir, legitimando la explotación económica. En resumen, a partir de la mitificación y el fetichismo, la ideología mestiza dominante confecciona un "indio" en estado de "primitivismo natural". En definitiva, se construye y pone en movimiento una ideología que al tiempo que justifica la posición privilegiada de la clase dominante mestiza, así como la subalterna del indígena, instaura un comportamiento paternalista y 
Desde la independencia de México, el grupo dominante en la región se constituyó por parte de criollos y mestizos que pasaron a cubrir el vacío de poder dejado por los españoles. Esta clase hegemónica regional, diversificada y no homogénea, intenta imponer sus intereses e ideología (la cual justifica su posición preeminente en la región), entrando en relación ya de cooperación o de competencia y conflicto (según la coyuntura y el momento histórico) con el Estado, actor que representa el núcleo de poder central (o, cuando menos, otro de los focos de poder a tener en cuenta en la configuración y desarrollo de las regiones). Asentados en las cabeceras rectoras económicas y políticas, basaron su poder en el monopolio del transporte, distribución y comercialización de los diversos productos agrícolas, tanto al interior de la región (fijando unilateralmente los precios), como intermediarios con el ámbito nacional. A su vez, y mediante este férreo control del tráfico arriero, de sus rutas y puestos secundarios (plazas de mercadeo y comercios regentados en propiedad por familias mestizas con lazos en los centros rectores), mientras compraban la producción local a bajo coste, distribuían a lo largo de la Sierra Norte productos manufacturados traídos de otros espacios regionales y nacionales, elevando notablemente el importe de éstos. En la Llanura Costera, además de controlar el comercio, la estrategia se centró en el acaparamiento de grandes extensiones de tierra destinadas a plantaciones, ingenios y ganadería extensiva. Las rebeliones totonacas contra este monopolio y las condiciones que se les imponían como peones en estos ranchos y haciendas, fueron sofocadas cruentamente, manteniendo la situación vigente y el sometimiento totonaco.

Con ello, y durante el siglo XIX y gran parte del XX, esta clase impuso su dominio económico, político y sociocultural en la región, sustentado en gran parte por el control comercial dentro de un modelo de mercadeo de tipo solar donde varias cabeceras rectoras y plazas secundarias no indígenas monopolizan el comercio, las instituciones políticas y controlan las comunicaciones, mientras en torno suyo, como planetas orbitando astros, comunidades dependientes producen en regímenes de sumisión y dependencia, a muy bajo coste, aquellos productos que las cabeceras, en relación al comercio regional y nacional (principalmente y para esta zona) demandan ${ }^{13}$. Es a partir de este modelo, como "región de refugio" dentro de un fuerte "proceso dominical" (Aguirre Beltrán 1991), que debemos comprender la articulación de la Sierra Norte de Puebla. En resumen, y para toda esta etapa, podríamos concluir que

“el control del poder político en la región está en manos de los grandes propietarios y comerciantes. Ellos, o personas incondicionales de ellos, ocupan los cargos de presidentes municipales y otras autoridades civiles. Mantienen su dominación tanto por el control que ejercen sobre la economía de la región como por el control ideológico y la represión. [...] Muchos de los grandes propietarios tienen bandas

asimétrico en las relaciones entre los grupos. Es precisamente en dichas relaciones, comportamientos y prácticas intergrupales donde se objetiva la ideología mientras se recrean en el día a día, configurando los marcos de poder que constriñen la comunicación e interrelación entre las diferentes culturas de clase. Estas prácticas van desde discursos y narrativas que la reproducen socialmente en la cotidianidad hasta la discriminación en diferentes escenarios, así como, y en no pocos casos, la violencia abierta y manifiesta.

13 No obstante, y caso que en otros modelos no se produce, este tipo de mercadeo solar permite que se establezcan una serie de intercambios horizontales entre las diversas comunidades implicadas, a partir de un sistema de tianguis semanales donde los productores pueden acudir a vender sus productos en condiciones de igualdad con el resto de los asistentes, sean estos de la misma comunidad o de otras vecinas. 
de pistoleros a sueldo que asesinan a los dirigentes campesinos o a quienes intenten enfrentárseles. Este grupo de poder tiene el apoyo de las instituciones del gobierno y de los aparatos del Estado" (Steffen y León 1990: 212-213).

Mientras, en la costa, el control y monopolio de tierras y de la mano de obra indígena se erige como principal estrategia de acaparamiento de riqueza y poder de la clase no totonaca. El mercadeo en esta zona de la región corresponde a un tipo dendrítico ${ }^{14}$ de carácter vertical más próximo a la lógica capitalista, destinado al mercado nacional e internacional antes que al interno y en el que los campesinos tienen una posición de desventaja. Las movilizaciones contra este modelo son aplastadas, permitiendo la continuidad de la estructura de tenencia de tierra y los modelos productivos basados en la explotación de los indígenas como mano de obra en haciendas, ingenios y ranchos de ganadería extensiva.

Este statu quo se mantuvo con escasas modificaciones hasta la década de 1970. Durante los años 40 se fue produciendo un lento pero decisivo viraje de la producción agrocomercial de la caña de azúcar hacia el café. Si bien la caña no desaparece, sí decae notoriamente en producción, perdiendo terreno ante el café que, aunque cultivado desde antes, es ahora cuando comienza a despuntar como nuevo cultivo comercial. Si exceptuamos esta variación en la tendencia productiva, la situación imperante no se ve modificada de manera remarcable. Los grupos de poder no indígenas permanecen como hegemónicos en la dirección política y económica de la Sierra Norte, controlando las cabeceras municipales y centros rectores político-económicos primarios y secundarios (para la Sierra Norte, Huauchinango, Xicotepec de Juárez, La Ceiba, Zacatlán, y para la Llanura Costera, Poza Rica, Tuxpan, Papantla) y las comunicaciones, así como, cuando pueden (lo cual es frecuente), las presidencias de las comunidades importantes a lo largo de las rutas comerciales, allí donde acaparan grandes extensiones de tierra, regentan negocios y ejercen como intermediarios entre este espacio local productor y las cabeceras y poblaciones secundarias no indígenas.

Los años sesenta, y especialmente los setenta, supusieron la irrupción de un nuevo actor en escena (o quizás y más correctamente, la reorientación de la postura y actividad de uno de los actores ya presentes), hecho que modificaría marcadamente la situación. Si bien desde los años treinta (como embrión del programa inversionista posterior) el Estado había empezado a intervenir en la región, impulsando lo institucional y corporativo en las comunidades agrícolas de la zona (a las cuales dota de tierra en forma de ejidos e instituciones administrativas propias, apoyando su creación o reforzando las existentes), en un intento de atraer hacia sí dichos espacios sociales como tentativa de ganar apoyos frente al control de la clase dominante regional (y con ello ganando poder efectivo y peso social frente a dicho grupo), no será hasta los años setenta que las actividades del Estado reconfiguren efectivamente el espacio de la Sierra Norte.

La actuación de este foco central de poder se dirigió, principalmente, en dos direcciones: por un lado, la creación y puesta en marcha de instituciones económicas gubernamentales con pretensión de instaurar una dependencia (y con ello control) de las comunidades y pueblos respecto al Estado, minando al tiempo el dominio económico del grupo social hegemónico a nivel regional. Estas instancias econó-

14 Para una ampliación de las características y consecuencias de los tipos de mercados solar y dendrítico, ver Nash (1979), de la Peña (1986), Smith (1991) o Velázquez (1995). 
micas son, entre otras y principalmente, el INMECAFÉ ${ }^{15}$ y el CONASUPO ${ }^{16}$. En segundo lugar, y no menos importante, con la construcción de un sistema de carreteras en la región que permitieran la entrada de tráfico rodado en las comunidades dispersas en la Sierra y la Costa. Con la consumación durante los años setenta de este plan de carreteras y mejora de las comunicaciones a lo largo de toda la zona, el gobierno consigue romper definitivamente el monopolio mestizo sobre el comercio y sus rutas, desapareciendo paulatinamente la arriería, y quedando muy mermado el sistema solar de mercadeo (y su fácil control por parte de la clase dominante) que caracterizaba la región. Con ello, la elite regional queda desplazada de su posición hegemónica, aunque sin desaparecer; una posición preeminente que ahora ocupará el Estado como intermediario y actor principal hasta los años noventa.

A su vez, y al amparo de las nuevas condiciones, en los años del desarrollismo surgen cooperativas de campesinos que rivalizan y compiten con los grupos de control económico tradicionales, ahora, y roto su monopolio, con menor poder de actuación. Por ejemplo, la exitosa cooperativa indígena Tosepan Titataniske, con sede en Cuetzalan.

Es el periodo que podríamos denominar como desarrollista y que abracaría desde los años setenta hasta los noventa, momento en que el gobierno se retira de escena y se instaura la nueva etapa que rige hasta ahora: la neoliberal.

Debido a la remodelación estructural, las condiciones de los campesinos productores mejoran, pero, tal y como señala Emilia Velázquez, la facción mestiza, aunque mermado su papel, no desaparece y sigue comprando parte de la producción a los campesinos. Muchos de éstos, con mayor libertad de elección gracias a las nuevas opciones abiertas, venden parte del café producido al INMECAFÉ, mientras otra parte la destinaban a acaparadores privados locales.

Finalmente, los años 90 suponen una nueva reformulación en la zona. Después de la intervención estatal desarrollista se abre una etapa neoliberal que conlleva la retracción del gobierno de la zona y la desarticulación de las instituciones intermediarias paraestatales (primero, en 1992, el INMECAFÉ; pocos años después, en 1999, el CONASUPO). Con ello, la economía de libre mercado se ha impuesto en la región, a medio camino entre el monopolio mestizo (clase que vuelve a ocupar el puesto del que nunca fue totalmente desbancada) y de diferentes compañías privadas tanto nacionales como internacionales, con la consecuente liberalización de los precios y desamparo de los productores. Esta desregularización conlleva la caída del precio del café con las nuevas condiciones internacionales de producción de dicho producto. La entrada en el mercado de países asiáticos como productores a menor precio, sin ninguna institución estatal reguladora, hace desplomarse el valor del café, dejando de ser rentable para los productores mexicanos. El campesinado ha vuelto a las condiciones difíciles que parecía haber transcendido; duras condiciones en las cuales, sin alterna-

15 Organismo paraestatal fundado en 1958 como regulador de los precios, fijando un precio mínimo que retribuía adecuadamente a los productores, además de intervenir en la compra del producto, así como realizaba pagos por anticipado a cambio de cosecha, con una remuneración posterior en concepto de alcance, según el resultado de la venta en el nivel nacional e internacional.

16 Institución creada por el gobierno en 1965 destinada a promover el desarrollo económico y social del país a partir de la regularización de los mercados de los productos básicos o de subsistencia popular, estableciendo una mediación entre los productores y los consumidores, evitando con ello intermediarios deshonestos y/o ineficientes. Así como y al mismo tiempo, pretendía asegurar el abasto de productos básicos para aquellos consumidores y productores con bajos ingresos. 
tiva a los cultivos antaño rentables (café y caña de azúcar), ha tenido que recurrir a la emigración y a la proletarización en condiciones muy desventajosas. Una situación estructural que, por el momento y hasta la actualidad, se mantiene.

Este desarrollo desde la Colonia hasta la actualidad, con la salvedad del periodo "desarrollista", mantiene a los totonacos en una situación subalterna frente a los castellanos y criollos, en primer lugar, y posteriormente a los criollos y mestizos, erigidos en cultura nacional y acaparadora de las instituciones de poder y económicas representantes del nuevo Estado-Nación.

Es en este contexto de desigualdad en el que, durante mi dilatado trabajo en la zona, acudí a varios episodios espacialmente separados entre sí donde se invocó al Totonacapan en conversaciones o discusiones cotidianas ${ }^{17}$. En ellos, y en referencia al escenario de relaciones sociales arriba descrito, interlocutores totonacos, con mayor o menor nivel de excitación y con diferentes palabras, recordaban que estábamos en el Totonacapan, lugar de totonacos. Con ello enfatizaban una suerte de relación ancestral y de pertenencia con el entorno físico que debiera resituarles dentro de las dinámicas sociales; dinámicas que les mantienen como subalternos a un grupo no indígena que ha asumido el papel hegemónico dentro de la zona que, nominada como Totonacapan y dentro de una ideología localista, pertenecería por derecho histórico a los indígenas de cuyo nombre deriva.

Es decir, y como es lógico, los totonacos reinterpretan su posición con relación al lugar que ocupan en las dinámicas de poder regionales, en función de sus propias formulaciones culturales y sus intereses particulares de clase. $\mathrm{O}$ como lo plantea Lomnitz-Adler, "una ideología localista constituye una especie de replanteamiento, desde el punto de vista de la cultura íntima, de la cultura de relaciones sociales" (1995: 54). Con ello, "las interpretaciones internas (íntimas) de la cultura de relaciones sociales también se subordinan a la lógica de la reproducción cultural de las culturas íntimas", lo cual "puede llegar a generar tensiones para la hegemonía regional" (ibid. 1995: 51). Y el Totonacapan es uno de los recursos a los que apelar en dicha reinterpretación y resituación dentro de la "cultura de relaciones sociales" y la comunicación entre "culturas íntimas" que se produce en el seno de aquélla.

\footnotetext{
Uno de ellos, en una cantina donde el propietario, un totonaco de mediana edad amigo nuestro, arengaba a un cliente no indígena, camionero fuereño que había detenido su vehículo para tomar algo. En su discurso, cargaba contra el racismo hacia los totonacos, a los que se refieren despectivamente como "nacos", tildándolos de primitivos y salvajes. Pero esto es el Totonacapan, prosiguió, tierra de totonacos. Decía esto con orgullo, añadiendo que, si alguien sobra, son los no totonacos, pues esta es su tierra. Otro episodio lo vivimos en la zona de Yohualinchan, donde durante la Semana Santa, un habitante totonaco nos recordaba en sus explicaciones sobre los rituales componentes de los festejos que estábamos en el Totonacapan, territorio de los totonacos. Pareciera que esa alusión, incluir Totonacapan en la explicación, aclaraba automáticamente la totalidad del discurso. Pero, por si acaso no fuera así, el señor añadió: "vamos, nuestra tierra". Un tercer ejemplo tuvo lugar en el extremo norte de la región, en un acto político. El gobernador de Puebla había acudido a inaugurar una carretera al tráfico rodado en la zona. Recurriendo a la etnicidad como reclamo electoral, llevaron a un hombre y una mujer vestidos al estilo totonaco, en una banal folclorización de lo étnico. Cuando hablaron en totonaco al público congregado, dos señores de San Pedro Petlacotla que nos acompañaban, totonaqueros (como se referían a sí mismos) de edad avanzada, criticaron entre bromas la forma de hablar en totonaco de aquellos oradores invitados. Uno de ellos, entre chanzas, me dijo: "Seguro que no es ni del Totonacapan”. Cuando le pregunté a qué se refería con dicho comentario, simplemente dijo: "que no es de aquí, de los nuestros". Es decir, Totonacapan en las versiones totonacas de quienes lo manejan con intenciones étnico-políticas, equivale a ser totonaca o, de no pertenecer a tal etnicidad, ser un advenedizo en territorio ajeno. La vinculación del espacio regional con el etnónimo avala la pertenencia ancestral, previa a aquellos fuereños (mestizos, nahuas, tepehuas...) que en diferentes momentos han ido llegando y con los que los totonacas han desarrollado diferentes tipos de relaciones sociales.
} 
Partiendo de este cuadro y desde esta perspectiva centrada ${ }^{18}$, podríamos definir el Totonacapan como el espacio regional donde su invocación como concepto entra dentro de las relaciones entre grupos sociales enfrentados, y en las reivindicaciones de aquel subordinado (los indígenas) frente al sector hegemónico que monopoliza las instituciones de poder y económicas (los mestizos o no indígenas) en el espacio territorial en el que dicho concepto (Totonacapan) resulta o puede resultar un recurso de poder históricamente heredado. Es decir, podríamos comprender el Totonacapan como un elemento simbólico que entra en el lenguaje de comunicación de clases dentro de una "cultura de relaciones sociales" y permite a una cultura íntima (la totonaca) y dentro de su ideología localista, un intento de reinterpretación de su posición en dicha "cultura de relaciones sociales". En este sentido, el Totonacapan podría ser definido en la actualidad como aquel espacio donde se recurre a dicha idea para emplearla en el enfrentamiento de grupos en relación a dicho espacio.

Este empleo del término adquiere sentido en el ámbito de las relaciones de poder entre culturas íntimas, allí donde apelar a él entra en la competencia y conflictos entre los grupos hegemónicos y favorecidos de la zona (mestizos) y aquellos subalternos sometidos a la hegemonía de los primeros (indígenas). En esta línea, se convierte en herramienta simbólica dentro de un desigual enfrentamiento entre dos bloques: los indígenas totonacas y los mestizos (grupos no homogéneos y desiguales a su interior), esgrimidos por los primeros como elemento étnicamente unificador en su lucha frente al acaparamiento del poder y sus instituciones por parte de los no indígenas (mestizos o criollos), así como avalador de sus reclamaciones (presentándose como los "verdaderos" pobladores del territorio así denominado). El Totonacapan se introduce en las relaciones sociales de la zona un como marcador étnico en el autorreconocimiento (Barth 1976), mientras otorga a aquellos que en parte por él se definen identitariamente (los totonacas) derechos de antigüedad que validan sus reclamaciones frente al control económico-político mestizo, así como en su lucha por mantener sus tierras y/o el control político en sus comunidades. En este empleo social e ideológico del concepto, se apela a algunas de las formas que he venido repasando en este texto, principalmente, la étnico-cultural y la política (con sus tres centros rectores prehispánicos: El Tajín, Yohualinchan y Cempoala, esos "tres corazones" de donde, de acuerdo con algunas acepciones, se hace derivar el término totonaca). Esto, como resulta evidente, no es que valide dichos criterios (que ya he descartado para la actualidad), sino que los emplea en el contexto que yo propongo como común y definidor de dicho ámbito regional: su uso en la comunicación y conflicto entre grupos observados entre sí como étnicamente diferentes y en relación a sus derechos sobre el espacio al que el término idealmente se refiere y que ambos habitan ${ }^{19}$ en condiciones desiguales.

18 Paul Liffman resalta la dificultad y el reto que supone "reconciliar nociones estructurales de región geográfica, tenencia y uso de la tierra con el emplazamiento fenomenológico de la gente y su apropiación de prácticas y discursos globales". Es en este sentido que toma de Nicholas Entrikin los enfoques "descentrados" y "centrados" o la diferencia que introduce Henri Lefebvre entre la "base de acción objetiva" y el "campo de acción" indéxico del actor (Liffman 2012: 56).

19 No obstante, existe un intento de "reversión” de este uso político del Totonacapan. Los mestizos, a través de instituciones y entidades controladas y gestionadas por ellos, están recreando un Totonacapan desprovisto de la vertiente reivindicativa que en la invocación totonaca tiene o pudiera tener. En esta versión, el concepto se rescata de la historia muerta, de un pasado agotado, como un espacio folclórico del "indio de estado" (Galinier 2008). Se presenta como reclamo turístico donde la indianidad funge como atractivo folclórico y sus represen- 
Con ello, rastreando allí donde este concepto históricamente heredado desde diversas fuentes entra en el imaginario colectivo y se manifiesta en las relaciones sociales como recurso simbólico y marcador de pertenencia étnica, se podría delimitar el espacio que, de manera ideal, el Totonacapan abarca como región hoy en día, devolviendo éste a aquéllos que realmente le confieren "existencia" en sus relaciones espacialmente situadas: los actores sociales.

\section{Conclusiones}

La noción de región es sin duda de gran importancia para las Ciencias Sociales. Como idea, la región permitió transcender los restringidos estudios de comunidad, los cuales, aunque en muchos casos loables en su calado y profundidad, dejaban a las poblaciones en un vacío, ajenas a contextos más allá de su existencia espacialmente localizada. Pero esta importancia cardinal, aunque innegable, no acredita su empleo de forma indiscriminada, ajeno a criterios justificadores en su delimitación y uso. Por otro lado, y aunque dichos criterios sean apropiados para un momento histórico determinado (como es el caso que nos ocupa), no debieran ser petrificados y perpetuados como características inmanentes a una realidad tomada por estática. Si aceptamos que las regiones son formaciones cambiantes de acuerdo con la diacronía de sus desarrollos, la revisión de los criterios con que se las define según el momento histórico contextual es una necesidad imperante.

Es decir, antes que una entidad dada o formación existente que el investigador extrae a partir del análisis objetivo de una serie de rasgos diagnósticos preexistentes en una realidad concreta, debe ser entendida como una idea, una noción heurística que el propio investigador, a partir de criterios coherentes respecto al espacio que estudia, impone a la realidad para hacerla manejable y dotarla de sentido en su articulación en niveles: la comunidad con la región, y ésta con contextos mayores (nacionales e internacionales). Es un concepto "bueno para pensar" (Van Young 1992), una herramienta que permite transcender la localidad para insertarla en redes relacionales de mayor extensión y que permite comprender mejor las complejidades y desarrollos de la misma comunidad como parte integrante de un sistema mayor, con el que interacciona en mutua (aunque desigual) influencia. Pero hay que tener siempre presente que el concepto región "no expresa una definición real, no es un concepto unívoco (monotético) en torno al cual pueda construirse un tipo ideal o una teoría general de las regiones. Por el contrario: es un concepto histórico, politético, cuyo significado se modifica por circunstancias de tiempo y lugar" (de la Peña 1981: 125-126). Y es precisamente por tener este enunciado muy en cuenta que debemos revisar en cada caso concreto y con periodicidad temporal la pertinencia del contenido que define cada región. Su potencialidad de cambio (ese carácter histórico) y su inaplicabilidad en la construcción de teorías generales de las regiones hacen que cada caso sea único y que lo que puede seguir siendo válido en la definición de otra región no lo

taciones (rituales y prácticas curativas, danzas, vestimentas, peinados, artesanías...) se muestran desconectadas de su uso social, como piezas de museo que invisibilizan al "indio" actual y sus circunstancias. Así apropiado, la clase hegemónica resignifica el Totonacapan, domesticando su uso por desposeerle de las reclamaciones sociopolíticas que en el discurso totonaca muestra, mientras extrae de ello un rédito económico a partir del turismo, valiéndose de lo exótico y esotérico del "indio de estado" como propaganda. 
es en el caso que nos atañe, e incluso lo que podía ser válido en la definición de una misma región en un momento histórico concreto no lo sea en la coyuntura presente, existiendo otros factores en su cohesión o habiendo dejado tener existencia teórica como tal.

\section{Referencias}

Aguirre Beltrán, Gonzalo. 1991. Regiones de refugio: el desarrollo de la comunidad y el proceso dominical en Mestizoamérica. Obra antropológica, IX. México: Fondo de Cultura Económica, Universidad Veracruzana, Instituto Nacional Indigenista, Gobierno del Estado de Veracruz.

Barth, Fredrik. 1976. «Introducción», en Los grupos étnicos y sus fronteras, Fredrik Barth, comp., pp. 7-49. México: Fondo de Cultura Económica.

Boehm, Brigitte. 1997. «El enfoque regional y los estudios regionales en México: Geografía, Historia y Antropología». Relaciones. Estudios de Historia y Sociedad 72: 15-46.

Chenaut, Victoria. 1995. Aquellos que vuelan. Los totonacos en el siglo XIX. México: Centro de Investigaciones y Estudios Superiores en Antropología Social.

De la Peña, Guillermo. 1981. «Los estudios regionales y la Antropología Social en México». Relaciones. Estudios de Historia y Sociedad 8: 43-93.

—. 1986. «Los campesinos indígenas y las estructuras de mercadeo». México Indígena 12: 27-32.

—. 1999. «Las regiones y la globalización: reflexiones desde la Antropología Mexicana». Estudios del Hombre 10: 37-57.

Fábregas Puig, Andrés. 2010. Configuraciones regionales mexicanas. Un planteamiento antropológico. Volumen I. México: Gobierno del Estado de Tabasco, Centro de Estudios Superiores de México y Centroamérica, Universidad de Ciencias y Artes de Chiapas.

Frank, André G. 1978. Capitalismo y subdesarrollo en América Latina. México: Siglo XXI Editores.

Fuentes Aguilar, Luis. 1972. Las regiones naturales del estado de Puebla. México: Instituto de Geografía, Universidad Nacional Autónoma de México.

Galinier, Jacques. 2008. «Indio de estado versus indio nacional en la Mesoamérica moderna», en Raíces en movimiento. Prácticas religiosas tradicionales en contextos translocales, Kali Argyriadis, Renée de la Torre, Cristina Gutiérrez y Alejandra Aguilar, coords., pp. 111-127. México: Centro de Investigaciones y Estudios Superiores en Antropología Social, Centro de Estudios Mexicanos y Centroamericanos.

García Martínez, Bernardo. 1987. Los pueblos de la Sierra. El poder y el espacio entre los indios del norte de Puebla hasta 1700. México: El Colegio de México.

Gatti, Luis María. 1987. «La Huasteca Totonaca (u 'otra vez la cuestión regional')», en La costa totonaca: cuestiones regionales II, Luis María Gatti y Victoria Chenaut, coords., pp. 3-24. Cuadernos de la Casa Chata 158. México: Centro de Investigaciones y Estudios Superiores en Antropología Social.

Kelly, Isabel T. y Ángel Palerm. 1952. The Tajin Totonac. Part 1. History, Subsistence, Shelter and Technology. Smithsonian Institution, Institute of Social Anthropology 13. Washington, D.C.: U.S. Government Printing Office.

Krickeberg, Walter. 1933. Los totonaca. Contribución a la etnografía histórica de la América Central. México: Secretaría de Educación Pública. 
Liffman, Paul M. 2012. La territorialidad wixarika y el espacio nacional. Reivindicación indígena en el occidente de México. Zamora: El Colegio de Michoacán, Centro de Investigaciones y Estudios Superiores en Antropología Social.

Lomnitz-Adler, Claudio. 1995. Las salidas del laberinto. Cultura e Ideología en el espacio nacional mexicano. México: Joaquín Moritz, Editorial Planeta.

Malinowski, Bronislaw y Julio de la Fuente. 1957. «La economía de un sistema de mercados en México. Un ensayo de etnografía contemporánea y cambio social en un valle mexicano». Acta Anthropologica, Época 2, Vol. I, nº 2.

Masferrer Kan, Elio. 2006. Cambio y continuidad entre los totonacos de la Sierra Norte de Puebla. Tesis de Maestría. Universidad Iberoamericana, México.

Mintz, Sidney W. 1998. «The Localization of Anthropological Practice: From Area Studies to Transnationalism». Critique of Anthropology 18 (2): 117-133.

Murra, John. 1975. Formaciones económicas y politicas del mundo andino. Lima: Instituto de Estudios Peruanos.

Nash, Manning. 1979. «El mercado y las economías campesinas indígenas», en Campesinos y sociedades campesinas, Teodor Shanin, comp., pp.144-159. México: Fondo de Cultura Económica.

Palacios, Enrique Juan. 1942. Cultura totonaca. El Totonacapan y sus culturas precolombinas. México: Ediciones encuadernables El Nacional.

Roberts, Bryan. 1980. «Estado y región en América Latina». Relaciones. Estudios de Historia y Sociedad 4: 9-40.

Ruiz Lombardo, Andrés. 1991. Cafeticultura y economía en una comunidad totonaca. México: Consejo Nacional para la Cultura y las Artes, Instituto Nacional Indigenista.

Smith, Carol. 1991. «Sistemas económicos regionales: modelos geográficos y problemas socioeconómicos combinados», en Región e historia en México (1700-1850). Métodos de análisis regional, Pedro Pérez Herrero, comp., pp. 37-98. México: Instituto Dr. Mora, Universidad Autónoma Metropolitana.

Van Young, Eric. 1992. «Introduction: Are Regions Good for Thinking?», en Mexico's Regions: Comparative History and Development, Eric Van Young, ed., pp. 1-36. San Diego: Center for U.S.-Mexican Studies, University of California.

Velázquez Hernández, Emilia. 1995. Cuando los arrieros perdieron sus caminos. La conformación regional del Totonacapan. Zamora: El Colegio de Michoacán.

—. 2001. «El territorio de los popoluca de Soteapan, Veracruz. Transformaciones en la organización y apropiación del espacio». Relaciones. Estudios de Historia y Sociedad 87: 16-47.

Viqueira, Carmen. 2001. El enfoque regional en Antropología. México: Universidad Iberoamericana.

Wallerstein, Immanuel. 2003. El moderno Sistema Mundial. México: Siglo XXI Editores.

—. 2005. Análisis de los sistemas-mundo: una introducción. México: Siglo XXI Editores.

Wolf, Eric R. y Ángel Palerm. 1992. Sistemas agrícolas y el desarrollo del Área Clave del imperio texcocano. México: Gernika. 